\title{
1. Literature review, research gap, industry and theoretical summaries
}

\section{LITERATURE REVIEW}

Before we examine our main hypothesis, we would like to present a historical fact about the history and evolution of modern Islamic banking. In the 1950s Ungku Aziz, the famed Malaysian economist, realized there was an underlying issue with savings in Malaysia. The main reason for savings was to perform Haji, which is the pilgrimage to Mecca. Typically, money was stashed throughout one's property, such as in the attic and under pillows. However, those savings were rarely enough, leading families to sell all their assets in order to complete Haji. This created a problem because once they returned to their homelands they were left with no land or other assets. Ungku Aziz observed that this could not be beneficial for either the economy or the Muslims in Malaysia, so he started to research riba (interest). His goal was to establish a fund which would allow individuals to complete Haji without the worry of riba, since it is forbidden. Following his research, in 1959 Ungku Aziz submitted "The Proposal to Improve the Economics of Haji Pilgrimage" to the Malaysian government. His proposal included the establishment of an organization which would provide savings and management of funds for pilgrimages to Mecca. [Conversation with Dr. Zeti about Tabung Haji]

The Malaysian government was unable to immediately decide on this issue. Instead, it called on knowledgeable individuals to attend a meeting for public discussion. The meeting had a monumental impact in that the proposal was widely accepted, giving the government incentive to move forward. In 1960 it formed the Working Group for the Welfare of Pilgrims, and in 1962 the government approved the group's White Paper. Later the same year the Malaysian parliament approved the Incorporation of Pilgrimage Savings Fund act, which resulted in the creation of the Pilgrimage Savings Corporation (Tabung Haji) in 1963. Tabung Haji may well be the first deposit-taking Islamic finance institution in the world, even before Dr. Ahmad Al-Najjar's Mit Ghamr Savings Bank of the same year. The Malaysian pilgrimage savings fund now accounts for nearly \$20 billion in managed savings for over nine million Malaysians. [Conversation with Dr. Zeti about Tabung Haji] 
Unlike conventional asset management-which has its own dedicated academic journals (e.g., the Journal of Portfolio Management, founded in 1966), thousands of scholarly articles stretching back nearly six decades, and more than a few Nobel Prizes 1 - scholarly research on multi-asset Islamic portfolio investing is thin to date. Research cited here, therefore, is derived from a vastly smaller set of articles. This literature review is confined to the following general topics:

- Islamic asset allocation

- Islamic equity indexes versus conventional equity indexes

- Islamic mutual funds versus conventional funds and/or Islamic equity indexes

- Sukuk as an asset category; sukuk performance against conventional indexes

- Islamic indexes and SRI

- General interest articles on investible sharia-compliant securities, for example mutual funds.

All the above fit within the very generic context of Islamic asset management. However, what is deliberately absent here are, as examples, an investigation of scholarly work on the sharia compliance of sukuk structures or the contractual relationship that may exist between retail Islamic banking customers and their financial institutions. Instead, the first goal of the literature review was to identify literature on multi-asset, sharia-compliant, optimized portfolio investing. Where that was absent, the second goal was finding literature that analyzed the market performance of an Islamic asset category. Avoided entirely are articles unrelated to asset management. This investigation did not delve into parallel Islamic banking issues related to other sectors, such as retail, corporate and investment banking, and did not investigate sharia issues in Islamic finance, which are treated elsewhere.

While several articles appeared in peer-reviewed journals, and a few in ranked journals, many were working or conference papers, or were found in much lower-ranked journals. Much of the scholarship begins in the mid-1990s, expands substantially in the early to mid-2000s, before dropping off by the time of the great global financial crisis, but seems to have had somewhat of a renaissance in the last decade.

That said, a literature review does yield some important results despite the infancy of the Islamic asset management industry. There have been serious studies on pieces of the sharia-compliant investible universe, where most scholarship examined the performance of sharia-compliant indexes and their assets traded in capital markets today. 
Interestingly, nowhere does the existing literature on various sub-components of Islamic asset management challenge or attempt to redefine the principles of asset management, which are more thoroughly discussed in the section "Modern Portfolio Theory and Theoretical Foundations of Asset Management" below. In other words, scholars who have to date approached Islamic asset management accept the general theories and methodologies of asset management, whether it be efficient allocation of portfolio securities, refined measurements of risk, or the comparative performance of conventional versus sharia-compliant assets. MPT and its derivatives remain the bedrock of investing, whether sharia-compliant or conventional.

With some exceptions, the large majority of existing scholarly literature on Islamic asset management seems to follow two primary threads, one focusing on the performance of sharia-compliant international, regional and national (almost always equity) indexes in comparison to conventional (non-Islamic) peer indexes, the other examining the performance of underlying securities (mutual funds, sukuk) and comparing them to the relevant conventional and Islamic indexes. A third thread is weak and more recent, comparing sharia-compliant equity investing to its cousin, SRI.

A disassociation of finance and economics was observed in the years preceding the Great Recession of 2008. International finance, especially, became more prevalent in the sense that it started contributing more to national wealth. Since the financial crisis, a stronger dependence on regulations and laws has been observed.

Taking into account ethical responsibility should be required after observing the hardship many faced following 2008. A study by Aziz, Idris and Sultan (2019) looks at both ethical and Islamic finance to evaluate the differences and similarities in these models. The goal is to combine two models which corporations can then build off of, thereby turning attention to how finance can play a part in supporting sustainable development around the world.

Ethical and Islamic finance are connected through their desire for sustainable finance which focuses on ensuring that future generations have access to the resources of today, resulting in economic growth and development. Though both have a similar focus, each can contribute insights to the other. For example, ethical finance includes observing the effect on the economy, society and environment, whereas Islamic finance has a foundation in sharia practices, which include four fundamental terms for transactions to be allowed. These include the requirement that an asset or real economic activity must back any transaction, the transaction must be deemed ethical by principle, all risk must be compensated with return and there is transparency between those involved.

Both types of finance include fairness, transparency, working toward a greater good, ensuring impermissible activities are not allowed and requiring social effects when considering business deals. By including these values, 
financial stability is encouraged at an institutional level. When these values are not observed, issues typically surface, including a deterioration in ethical beliefs and a decrease in accountability. Both of these issues, plus many more, then lead to financial systems which are instable. These values lead to some concerns. For example, despite the desire for sustainability in economics, society and the environment, there is still a need to be profitable. In current times, both ethical and Islamic finance can play a role in achieving these goals.

As a whole, the finance sector still has obstacles to overcome. These include creating accepted standards, which includes a governance structure when dealing with projects and how they are managed throughout their existence. Islamic finance already has a procedure in place which reviews for sharia compliance; however, a financial measure is lacking. The use of value-adding or value-based measures is being considered, following a sharia check.

Knowledge of both ethical and Islamic finance is required in integrating both concepts to achieve sustainability. Economic sustainability is not the only topic of interest, as the environment and society as a whole could benefit from collaboration between these two fields.

For collaboration to work, both forms of finance will need to clearly state the intended goals of such a combination. Following this, a mechanism can be produced to evaluate the influence of each type of finance. The goal for finance is not only to work toward a stable and resilient economy, but also to provide a foundation on which to create benefits that place a focus on societal and environmental sustainability as well.

Common among all scholarship to date related to Islamic asset management was an effort to use advanced contemporary measurements of risk and reward that are identical to the statistical and mathematical tools commonly used in conventional asset management. This is as it should be, since nearly all of Islamic asset management, and the research done on it, is both fundamentally secular and quantitative in nature. As a result, most academic works feature historically common and even some newer measurements such as the Sharpe ratio (and adjusted Sharpe ratio), Conditional Value at Risk, Continuous Wavelet Transform, Paired Sample t-Tests and, of course, positive and negative correlation (and autocorrelation), with many other measurements of variance and return used in comparing Islamic and non-Islamic pairs.

Islamic equities have been the subject of the bulk of scholarship in this subset of work on Islamic finance. Works concentrating on the performance of Islamic indexes versus their conventional peers include Hakim and Rashidian (2004), Girard and Hassan (2008), Guyot (2011), Jain (2012), Walkshäusl and Lobe (2012), Affaneh, Boldin and Albohali (2013), El Khamlichi, Arouri and Teulon (2014), Ashraf (2014), Dewandaru et al. (2015), Yilmaz et al. (2015), Charles, Darné and Pop (2015), Nasr et al. (2016), Alam, Arshad and Rizvi (2016), Trabelsi and Naifar (2017), Saâdaoui, Naifar and Aldohaiman (2017), 
Abu-Alkheil et al. (2017), Umar (2017) and Tukenmez, Saka and Kizgin (2019). The authors mostly discovered the outperformance, or at worst neutral performance, of Islamic equity indexes compared to their conventional peers, with some (e.g., Charles, Darné and Pop, 2015) indicating risk variance to conventional peers in certain time periods, in part because of a higher concentration in certain industries, and an explicit reduction of industry diversity among index components; these findings are also largely supported by Balcilar, Demirer and Hammoudeh (2015). Over time these studies have become more sophisticated. While Tukenmez, Saka and Kizgin (2019) use a less sophisticated return model with standard deviation and correlation included (indicating outperformance of sharia indexes versus conventional peers), Ashraf (2014) uses a multi-equation framework in an effort to "smooth out" the results due to index providers using different methodologies to construct their indexes (S\&P and Dow Jones using market capitalization on the one hand, and MSCI and FTSE using book-to-market on the other). Yilmaz et al. (2015), meanwhile, uses dynamic conditional correlation and dynamic equicorrelation to examine correlation among Islamic equity indexes in an effort to improve portfolio asset diversification for index investors (although, unfortunately, the authors incorrectly cite $\$ 70$ billion in Islamic mutual funds as part of increased demand from a broader Islamic asset management industry, yet don't point out that even using their incorrect number they still show that under $4 \%$ of Islamic finance assets are in mutual funds).

Conclusions from these articles on Islamic equity indexes generally relate to the source of the outperformance or neutral performance being derived from the nature of sharia-compliant investing, where financial and highly leveraged businesses are prohibited but at the same time are more volatile than the balance of the index composition. The great financial crisis of 2008 exposed investors worldwide to the perils of owning shares in financial services companies reliant on phantom derivative revenue and loans made during times of capital glut, or in heavily leveraged companies that succumbed or nearly died during the subsequent credit crunch. In such times sharia-compliant investing can intuitively be more rewarding as both debt and derivatives are shunned. There were, of course, contradictory findings as well, indicating that some Islamic indexes underperformed, but these results are admittedly indecisive as they were mostly drawn from single-country comparisons during restricted time periods. A good summary of indications both in favor and against the outperformance hypothesis of Islamic indexes is found in Alexakis, Pappas and Tsikouras (2016), which separately also describes the outperformance of Islamic indexes during times of crisis, and the beneficial results of optimizing a global conventional equity portfolio with the addition of sharia-compliant shares. A more recent and thorough study of the benefits of sharia diversification can be found in Bahloul, Mroua and Naifar (2017), where regional markets 
were segregated into their respective conventional and sharia-compliant equity indexes and then tested for diversification benefit for U.S.-based equity investors. One of the most important findings of Bahloul, Mroua and Naifar (2017) was the clear benefit of adding Islamic equity securities to a domestic U.S. portfolio during times of financial market troubles, further underscoring the safe-haven nature of sharia investing during economic crises.

On investigating literature related to Islamic indexes and their conventional peers, one discovers that an entire sub-family of literature exists on the behavior and components of Islamic equity indexes alone. Most of this literature, and others, points out the high concentration of certain industries in Islamic indexes and the absence of conventional financial services, which tends to skew their risk compared to conventional indexes. These works include Naifar (2016), Mazouz, Mohamed and Saadouni (2016), el Alaoui et al. (2016), Ashraf et al. (2017) and Chen and Ngo (2016), as well as others. While outside the scope of this study, each of these works indicate some form or other of unique behavior of Islamic equities. For example, Naifar (2016) links Islamic market behavior to major global macroeconomic and financial market conditions, linking sharia index performance particularly to sovereign credit, while el Alaoui et al. (2016) and Ashraf et al. (2017) question whether sharia screening for levels of corporate debt forces investors to choose stocks in companies with suboptimal capital allocation. Asset managers who opt for Islamic investing should pay heed to these findings and anticipate the potential for predicted outcomes.

Relevant to this book, Camgoz, Kose and Seval (2019) provide a complete overview of Islamic equity index studies to date, pointing out that classic investment return literature will normally conclude that investment constraints will by nature reduce diversification and shift the Efficient Frontier lower and to the right, that is, higher risk with less return. They indicate that to date 11 such index studies mostly show Islamic indexes outperforming conventional peers. But the picture is more nuanced. There are factors at work in developing and developed economies that will alter the performance of equity markets, for example the U.S. and the U.K. markets are populated with a much larger number of large-capitalization stocks, while Malaysia and Turkey have much fewer. The authors conclude that there are "no statistically significant differences between the risk and return characteristics of Islamic indices and their conventional counterparts," and "Islamic index investors have not incurred additional costs in the period examined" (2002-2017). This is welcome news for would-be Islamic portfolio investors who may have worried about underperformance or portfolio costs.

The other thread of equity-related scholarship followed the performance of Islamic mutual funds, mostly comparing them to conventional and/or Islamic market indexes or to peer conventional mutual funds. Among these were Elfakhani, Hassan and Sidani (2005), Abdullah, Hassan and Mohamad (2007), 
Merdad, Hassan and Alhenawi (2010), Hayat and Kraeussl (2011), Hoepner, Rammal and Rezec (2011), Binmahfouz and Hassan (2012), Rajjaque, Tang and Alam (2013), Abdelsalam et al. (2014), Kassim and Kamil (2012), Bahlous and Mohd. Yusof (2014), Dah, Hoque and Wang (2015), Makni, Benouda and Delhoumi (2015), Makni, Benouda and Delhoumi (2016), Abdul-Rahim, Abdul-Rahman and Ling (2019) and Shaikh et al. (2019). Here there were mostly negative reports, where the performance of a single sector or multiple sectors of Islamic mutual funds was found to be below that of their respective mutual fund peers or indexes. The results are to be expected where such underperformance is compared to indexes, and parallel the numerous examples of scholarship that derive the same results from conventional mutual funds. Collective investment vehicles have costs, and those costs will almost always create a gap between a fund's reported performance and that of its index. Very few managers of any stripe beat their indexes, including operating costs, and even less do so on a sustained basis. It should be no different for Islamic mutual funds.

Of note, however, are the findings of Shaikh et al. (2019), whose examination of the internal Pakistani mutual fund market indicates that sharia-compliant equity funds outperform conventional peers in terms of both risk and return, which their fixed-income cousins (a sukuk versus bond comparison) did not. Another study indicating at least slightly positive Islamic versus conventional mutual fund performance was delivered by Alwi et al. (2019), who compared 100 Islamic mutual funds to an equal number of conventional funds in the Malaysian market, focusing in particular on the years of the global financial crisis. And finally, Peillex et al. (2018) decompose the monthly return variability of Islamic mutual funds (equity only) in a fashion similar to which conventional equivalents have long been exposed. They consider factors unique to Islamic funds, that is, a smaller investible universe, bias toward low-leverage companies and a young industry (with presumably less-experienced managers), in an effort to understand why Islamic funds may underperform their conventional peers (which, they conclude, is mostly from inefficient active management).

Makni, Benouda and Delhoumi (2016) make an effort to differentiate between potential gauges of Islamic mutual fund success or failure by evaluating the funds by size, track record, institutional size and relationships, fees and other metrics, all such definitions having been previously applied in research on conventional mutual funds. Their conclusions are well in line with the results from the same studies of conventional peers. Size, age and institutional relations are all important factors in choosing funds. At the same time, Naqvi et al. (2018) indicate that there is no sign of a superior performance of Islamic mutual funds, in particular when accounting for asset classes and style (although their study may have been fatally hampered by examining only 
Malaysian and Pakistani equity funds, while at the same time the authors seem to have been deficient in defining their dataset by asset class, and suffered in their ability to produce common industry labels - and accompanying datafor various investment styles). At the same time, de la O González, Jareño and El Haddouti (2019) examined the performance of Islamic versus conventional stocks in ten traditional equity market sectors, including healthcare, technology, basic materials, consumer goods and so on. Importantly, their data time series is a respectable 20 years-January 1995 through December 2015 - a time period of multiple global market events, that is, pre-crisis, crisis and post-crisis. Measuring common performance factors such as Sharpe, Treynor, Sortino and Omega, the authors indicate that overall Islamic stocks outperformed on a sector-by-sector basis in nearly all cases, with stocks of conventional sectors outperforming in only a relatively few instances.

Among the two major threads of literature a frequent initial conclusion is found: commonly accepted asset pricing theories, but in particular the Capital Asset Pricing Model (CAPM), tell us that an unconstrained investible universe provides the highest degree of efficiency. Portfolios subject to constrained security selection will demonstrate less return and more risk than unconstrained portfolios (i.e., the Efficient Frontier will shift toward the right and down). However, empirical results can differ. It has been shown that constrained portfolios can have equal risk and return performance. While Dah, Hoque and Wang (2015) used an almost absurdly constructed dataset of Islamic mutual funds, ${ }^{2}$ they did show that a sharia constraint was not a barrier to some Islamic indexes and mutual funds achieving a neutral performance to their conventional peers. The abstract in Rajjaque, Tang and Alam (2013) is another example of authors pointing to a reduced investment set most probably producing different returns than equivalent conventional investing. Unfortunately Rajjaque, Tang and Alam (2013) is blemished by impossibly puzzling - and very wrong - statements about the Islamic mutual fund business. The authors state, "Moreover, because of the absence of an Islamic money market, the Islamic unit trust fund depends exclusively on the equity market for investment ..." The presence of many murabaha and sukuk funds in Malaysia (and available elsewhere internationally) seems to have escaped the authors' attention. Adding to the confusion, the authors write, "Islamic mutual funds are different from conventional mutual funds as they invest only in Shariah-compliant assets such as stocks and sukuks" [citing Abdullah et al., 2007; and Elfakhani et al., 2005]. "Conventional unit trust funds managers do not solely invest in equity markets compared with Islamic unit trusts; rather the fund may also comprise all types of risk-free investment" [citing Low and Ghazali, 2007]. These seemingly contradictory statements belittle the broad availability of risk-free equivalents in the Islamic finance market. 
Binmahfouz and Hassan (2012) made what might have been an important revelation, albeit perhaps inadvertent, relating to the performance of non-Saudi-managed Islamic mutual funds invested internationally (i.e., outside Saudi Arabia and the Gulf region) appearing to outperform conventional peers. While not specifically stated by the authors, it is obvious that they base their results on the assumption that such funds are actually managed inside the Kingdom, when in fact these are almost always sub-funds of much larger mutual funds managed in major capital centers such as London, Singapore or New York. Given the additional costs such sub-funds will always bear, it is indeed an achievement to show outperformance of Islamic mutual funds on a global scale.

Literature specifically on sukuk and sukuk markets was examined, but only where the articles had at least some relevance to Islamic asset management. Again, the literature was paltry. Explanatory, non-quantitative articles included Vishwanath and Sabahuddin (2009), Hanefah, Noguchi and Muda (2013), Alswaidan (2013), Wood, Mottahedeh and Wood (2014) (which may be wrongly inserted here as it dealt with taxation issues) and Kasuma and Silva (2014). These were essentially layman descriptions of a market that in all cases was very small and somewhat new at the time the articles were published (and, as will be indicated in the section "Results and Relevance of Analysis of the Islamic Investible Universe" in Chapter 3, still may be considered small and new). With sukuk outstanding increasing 141\% from year-end 2011 to 2017 ( $\$ 180$ billion to $\$ 434$ billion), these mostly verbal explanations of the sukuk market have become quickly dated.

Zulkhibri (2015) does justice in explaining the paltry nature of the literature on sukuk and sukuk markets. He identifies the minuscule number of articles relating to sukuk in peer-reviewed journals (only 12 articles on sukuk among 5,177 journals of economics, finance, accounting, business and management for the years 1990 through 2014), explaining structural and market reasons for the deficiencies.

Only six articles approached sukuk markets with a quantitative methodology, starting with Najeeb, Bacha and Masih (2014), who discovered low correlation among domestic sukuk issue prices, as well as identifying the poor secondary market trading in these securities and high correlation among international sukuk; while El Mosaid and Rachid Boutti (2014) compared the performance of sukuk versus bond portfolios in the Malaysian market, showing a significant and positive correlation. Godlewski, Turk-ariss and Weill (2011) also examined the Malaysian sukuk market, and identified the unusual phenomenon of corporate sukuk issuers facing negative equity price results after their new-issue announcements, versus those companies issuing conventional bonds. Naifar, Mroua and Bahloul (2017) use 2010-2014 quantile regression to analyze the Dow Jones and Malaysian sukuk and conventional Asian and 
Malaysian bond indexes to determine that indeed sukuk and bonds behave in a sufficiently dissimilar manner to be considered as complementary rather than identical assets. Azmat, Skully and Brown (2017), on the other hand, delve into sukuk and conventional bond structures in an effort to determine whether certain religious variables have an effect on ratings (they do), while at the same time concluding that Islamic bonds displayed resilience during the global financial crisis. The most recent addition to quantitative examination of sukuk market behavior is Hassan et al. (2018), which concludes that indeed sukuk offer diversification benefits to bond investors, showing similar characteristics during periods of market shocks, but with reduced volatility.

Very few articles were discovered that actually covered sharia-compliant, multi-asset-class portfolio investing. Dewandaru et al. (2014) were perhaps the only authors to approach the construction of diversified portfolios under optimized conditions. Unfortunately their fatal flaw was considering Muslims could actually have the choice to invest in conventional bonds (under sharia they cannot), and their significant constraint was using only data from Malaysian and U.S. markets, thus invalidating their research results for any examination of global multi-asset portfolios. Dewi and Ferdian (2012) also considered multi-asset investing, but it is difficult to put their work into context given the very narrow focus on just two markets, Malaysia and Indonesia, and the dual scope of examining and comparing the performance of sharia-compliant equity and sukuk funds in them. The Dewi and Ferdian (2012) research discovered to no surprise that sukuk funds had more stable returns than equity funds in these two markets. They also point to outperformance of Malaysian versus Indonesian equity funds, again without surprise given the decades-longer history of a rich and deep Malaysian asset management industry (and an inarguably less-volatile Malaysian economy), and reach the unsurprising conclusion that fund managers don't often beat their markets. In short, given that Dewandaru et al. (2014) and Dewi and Ferdian (2012) comprise the entire body of literature on multi-asset-class Islamic portfolio investing, one can conclude the available literature on this portion of Islamic asset management is indeed paltry.

Perhaps the single and only effort to date that examines the possibility of multi-asset-class Islamic portfolio investing has been Tumewang (2018). Here the author makes an almost tangential link to this study by considering Islamic pension funds, and his perception is that they should invest similarly to Yale University endowment. Tumewang (2018) links portfolio construction to the type of asset-liability management (ALM) typically used by pension funds, then proposes investing in real estate (via real estate investment trusts, or REITs), foreign equity (meaning non-Indonesian), infrastructure (without explaining how to invest in this category, nor in which type of securities), U.S. large-cap stocks (as opposed to foreign equity) and natural resources, creating 
an optimized allocation where the rate of expected inflation substitutes for the risk-free rate in the CAPM. While a unique case in observing the outcome of multi-asset-class Islamic investing, the relevance is limited due to the lack of any linkages to real-world capital markets' investible securities.

Generalist, non-quantitative compendiums of global Islamic mutual funds offerings, with their verbal descriptions, were made by Wilson (2007), Bose and Mcgee (2008) and Ghoul (2008), but they are today all very much out of date and the authors chose to pursue a very generalist, descriptive form of discussion. In this sense such articles cannot be considered scholarship.

Some effort has been made to compare sharia-compliant investing with SRI. Binmahfouz and Hassan (2012) search for statistical significance in the performance of Islamic and SRI indexes compared to their conventional peers and show there is none. They conclude, "... Muslim as well as [SRI] investors can choose investments that are consistent with their value systems and beliefs without being forced to sacrifice performance or expose [themselves] to higher systematic risk." Importantly, they enter the argument over whether constrained investment universes lead to lower portfolio performance and higher risk by stating that Islamic equity investors are by nature entering into a less-volatile market, where there are "financially stronger, more stable and profitable companies," which seems intuitively correct. Indeed, their citing the absence of Worldcom, Enron and Tyco from Islamic equity indexes gives comfort that there may be some truth here, but taking a much bigger picture one must also include the absence of hedge funds, derivative-based structured products and "full faith and credit" sovereign and corporate bonds from the sharia landscape, all of which contributed heavily to the global financial crisis. Future scholarship may penetrate the real world of conventional portfolio investing on the eve of the global financial crisis and create "what if?" scenarios speculating on what might have happened if, instead of the actual asset allocations of pension funds, endowments and insurance companies, asset managers had invested fully in sharia-compliant securities. The results could be surprising to many.

In the same context of SRI investing, Lashgari (2014) pursues the idea of a future fixed income security that is not tied to a fixed income, that is, the outcome of a security will be shared among participants in a fashion more akin to the GDP bonds previously proposed by Robert Schiller. The author envisions the returns of such securities being linked to future corporate profits, project returns or even economic output, making them more aligned with the concept of shared risk.

Again within the context of SRI investing, Nainggolan, How and Verhoeven (2016) argue that there is an implicit understanding that (1) financial shares are highly volatile and (2) the shares of highly leveraged companies are also highly volatile, so therefore sharia-compliant investing in shares will be less 
volatile, that is, over time will exhibit less risk and produce higher returns. Their findings indicate there are no advantages to investing in sharia-compliant equities if such investing is through Islamic equity funds which underperform their respective conventional peer funds over time (with the exception of the period covering the global financial crisis). However, while they have undertaken a comprehensive effort to measure the higher costs of sharia compliance, their use of heterogeneous data sources and a highly limited set of Islamic equity mutual funds indicates the possibility of erroneous conclusions. Further, their findings are contradicted by Reddy et al. (2017), where there is either neutral performance or outperformance of Islamic mutual funds versus conventional peers in the U.K. mutual fund market (and no significant difference between sharia-compliant and SRI mutual funds). Fu, Wright and Blazenko (2020) deliver advanced analytics in comparing constrained versus unconstrained portfolio investing, again simply looking at equities. They examine sin (alcohol, tobacco, gambling and adult entertainment), carbon (mostly petroleum-related firms) and sharia (which excludes mostly sin and financial stocks, plus over-leveraged companies) investing as different ethical constraints. The authors argue that past, mostly favorable, measures of ethical investing performance were misapplying optimal portfolio weights, which when corrected show there are no costs to avoiding sin or carbon and embracing sharia in portfolio investing (as measured by Sharpe ratio).

\section{RESEARCH GAP}

What the existing literature on Islamic asset management makes abundantly clear is that to date there is no comprehensive study available on global, multi-asset, sharia-compliant portfolio investing. There is equally no literature on the investible universe of Islamic mutual funds and ETF markets, the preferred securities of the "common man." Further, there is no literature on the combination of the two, answering the foundation question of this study: "What happens when one combines the Islamic investible universe with MPT? Will there be underperformance, outperformance or like performance of equally constructed portfolios?"

We know from the above literature that Islamic investment product managers exist, but little of the literature would have practical value to a practitioner who is seeking to create diversified, globally allocated, multi-asset-class, optimized portfolios from the securities in the investible universe that are acceptable and qualified from both professional asset management and regulatory perspectives.

While conducting a literature review on Islamic asset management, one quickly discovers an absence of "stepping stones" so common in other areas of scholarship. What this means is the absence of seminal early-stage work 
that establishes widely accepted knowledge, and from which springs forth new knowledge on a step-by-step basis. In the literature on conventional MPT (MPT) described below, one can clearly map the path of the construction of MPT, starting with the iconic Efficient Frontier envisioned by Markowitz in 1952, followed by the introduction of the risk-free rate by Tobin in 1958, and then completed by Sharpe in 1964 with his Capital Market Line and points of optimality (and, of course, all three won Nobel Prizes in economics for these contributions). For practitioners of asset management, these scholarly stepping stones provide the logic, the concrete foundation, from which managers can approach security selection and asset allocation. And, unsurprisingly, they do. Global asset management is founded on a bedrock of scholarship. Unfortunately, there is no parallel path in the existing literature on Islamic asset management, but rather a more random, non-linear approach to discussion and analytics of pieces to the puzzle.

What this means is that a would-be practitioner of Islamic asset management does not have much knowledge available from scholarly literature on how to proceed from scratch. Any efforts would have to be intuitive, since no descriptive literature exists on a holistic approach to Islamic asset management. No scholar has yet asked, "How does one begin selecting an investible universe of sharia-compliant assets? What does one do with these securities once they have been filtered and sorted? Can we use these securities to construct efficient portfolios? And does following this process in any way violate the principles of sharia?" Combined, these four questions form the essence of this study's Research Question, which is not answered in the existing literature.

This study makes an effort to approach Islamic asset management as a whole rather than performing an examination of its pieces, which essentially describes the nature of the existing literature on Islamic asset management.

\section{SUMMARY REVIEW OF THE GLOBAL ASSET MANAGEMENT INDUSTRY}

\section{Size and Nature of Global Assets Under Management}

The asset management industry comprises over $\$ 160$ trillion in professionally managed assets worldwide. Funds under management can be seen in various categories, as illustrated in a table provided by TheCityUK Fund Management. In the table, the division of assets and the dollar amount for each division is shown for various pension funds, mutual funds and insurance funds when dealing with conventional managed assets. As alternatives, SWFs, private equity, ETFs and hedge funds are options. In a figure also provided by TheCityUK, which gives numbers in trillions of dollars, the amount of profes- 
sionally managed assets for the years 2006 to 2016 are shown, the lowest being 58.7 in 2008 and the highest 101.0 in $2016 .^{3}$

We know intuitively that much of this managed wealth is owned by individuals and institutions (institutions often acting on behalf of individuals, such as pension funds, family trusts or insurance companies) in developed economies. Global wealth is measured at \$317 trillion (including non-financial assets). ${ }^{4}$ It is perhaps not possible to calculate the value of such assets owned by Muslims as credible wealth reporting is done by region (e.g., Europe, North America, Asia), where Muslims are widely distributed. However, one may make a generalist guess. Assume Muslims are 25\% of the world's population, then if equally wealthy they would own $\$ 79$ trillion of global wealth. But we know most Muslims are middle to low income, so we can arbitrarily deflate that number by $80 \%$, resulting in almost $\$ 16$ trillion in total Muslim wealth. Assuming that estimate is still too large, we can again arbitrarily discount that number by $50 \%$ and end up with just under $\$ 8$ trillion. Assuming $25 \%$ of that amount is financial assets, one can guess that Muslim-owned, professionally managed financial assets would be at least \$2 trillion, a not insignificant number.

\section{Role of Mutual Funds}

To focus more tightly on the purpose of this study, we examine the role of mutual funds in global asset management. Why mutual funds? Pension funds and insurance companies play an equally powerful role as intermediaries in the real economy by investing tens of trillions of dollars and their equivalents in other currencies in stocks, bonds, other credit vehicles, hedge funds and private equity. They also universally have the same general objective as mutual fund investors: maximizing return while minimizing risk through the application of MPT. But pension funds and insurance companies have special ALM issues. They are constrained in their portfolio allocations by regulators insisting on prudent investments to insure future liabilities (pension and insurance claims) are paid. And they are captive in the sense that no single individual can enter into and benefit from the investment strategy of a pension fund or insurance company. They represent specific investor groups and only those groups. Even with the most transparent investment policies, the large size and specific nature of these institutional investors makes their asset management profiles less appealing for what we are trying to achieve here in our discussion of Islamic asset management (although, of course, sharia-compliant pensions and insurers, or takaful, may benefit from applying Islamic asset management to their investment strategies and processes). To focus more tightly on the purpose of this study, we must include an examination of mutual funds as they are generally accessible to "common man" investors, which have very different 
investment profiles and investible universes when compared to institutional investors.

Mutual funds play several roles in asset management. First, they are the investment vehicle of choice for many individual investors, and not only in developed economies. Most individuals cannot hope to gain the benefits of investment diversification by themselves due to the complexity of global capital markets and the barriers to individuals accessing them. Mutual funds offer a portal into sophisticated professional asset management with low entry amounts. As stated by the International Monetary Fund (referring to mutual funds), "Financial intermediation through asset management firms has many benefits. It helps investors diversify their assets more easily and can provide financing to the real economy as a 'spare tire' even when banks are distressed. The industry also has various advantages over banks from a financial stability point of view." 5

Second, few investors choose a single-asset-class portfolio. Professional investors diversify investments across multiple asset categories: Cash, Fixed Income, Equity and Alternative Investments. Occasionally one will see debate on a fifth category, Real Estate, although industry practitioners more widely refer to real estate as part of the Alternative Investments category (this debate is not discussed here). Most professional asset managers achieve diversified portfolios through MPT, or optimizing risk and return to achieve predefined investment objectives. By analyzing, filtering and selecting mutual funds, an individual investor can hope to achieve an optimized portfolio.

Mutual funds - numbering over 114,000 worldwide and managing more than $\$ 49$ trillion in assets ${ }^{6}$ - play an important role in achieving diversification and portfolio optimization for many individual and a good number of institutional investors. ${ }^{7}$ Mutual funds, by nature, are the most democratic vehicle for individuals and many institutions to place their savings. They offer advantages to investing that few individual investors could hope to achieve on their own without mutual funds.

Further, absorption of mutual funds into an economy is considered an indication of that economy's strength and sophistication. Developed economies have much higher ratios of mutual fund AUM to GDP than less-developed economies. As an indicator, the Investment Company Institute provides a chart that shows the penetration of mutual funds in more- and less-developed nations. It shows that the more developed a country's stock market is, the more developed the fund industry is as a whole. This is based on regulated open-end long-term fund total net assets compared to stock market capitalization, both represented as a percentage of GDP. In this regard, Chile achieved 20\% mutual fund AUM to GDP, India is at 7\%, while Malaysia reached nearly $25 \%$. At the same time, Saudi mutual fund AUM to GDP is just under $6 \%{ }^{8}$ 
We look now at the fashion in which mutual funds are invested globally. They do play a significant role in the markets in which they are invested, whether money markets, fixed income, equities or alternative investments. Mutual funds are invested across all asset categories, and given the current $\$ 49$ trillion value of AUM in mutual funds worldwide, one may conclude that their role in capital markets is not insubstantial. In a graph, the total amount of worldwide regulated open-end funds are broken down into four divisions, including money market, bond, mixed/other and equity. This is shown for the years 2008 to 2017, which supports this claim.

We conclude by stating that any examination of an investible universe of mutual funds - Islamic or conventional - should allow us to obtain data on a set of investments for subsequent optimized portfolio asset allocations using these collective investment schemes as our source of securities. This will be discussed further in the next section.

\section{MODERN PORTFOLIO THEORY AND THEORETICAL FOUNDATIONS OF ASSET MANAGEMENT}

Perhaps since the time of Moses the axiom "don't put all your eggs in one basket" has been a golden rule in societies everywhere. The benefit of diversification is ancient wisdom. But how do we know we've achieved the optimal mix of assets?

The first to articulate this in a mathematical format was Markowitz (1952) in the landmark article "Portfolio Selection." It begins with the premise that "the investor does (or should) maximize ... expected ... returns." The author also posits "the investor does (or should) consider expected ... variance of return an undesirable thing." In other words, Markowitz (1952) explains that investors do (or should) seek higher profits with lower risk.

But Markowitz (1952) showed that one does not simply stuff one's portfolio with the single asset that individually has the best return and risk profile. Instead, expected price variations of each possible asset in one's investible universe must be measured against the expected price variations of all other assets in that universe. Markowitz (1952) mathematically showed that constructing a portfolio with uncorrelated (or less or negatively correlated) assets achieves the goal of higher profits with lower risk. Such portfolios are efficient in that they represent that set of portfolios where no additional return can be added without increasing risk. The set of such portfolios creates what is known as the Efficient Frontier.

We inherently know this is true, but the article "Portfolio Selection" showed us why. Optimal diversification is achieved by not only investing in uncorrelated (or less or negatively correlated) assets in a single asset class, but in investing across multiple asset classes, geographies and industries. 
Enormous work on asset allocation was done subsequent to Markowitz. Here we briefly examine only a very small sample of the literature after "Portfolio Selection," choosing within it only a few major works in subsequent decades, and a small selection of recent works of interest.

Tobin (1958) gave us a useful supplement to Markowitz, identifying the two choices all investors must make - one, the holding of riskless assets; the other, the holding of a portfolio of risky assets - and the tradeoff between the two. This concept was further evolved by Sharpe (1964), who introduced the addition of risky assets to a portfolio of risk-free assets, from which one could construct the Capital Market Line, and from there the optimal portfolio found at the point of tangency (equal slopes) with the Efficient Frontier. This "point of optimality" is the Holy Grail for portfolio investors. For the first time, intersecting Efficient Frontiers with the Capital Market Line removed the uncertainty of where one should invest one's assets. The only problem was that the entire construct was built on estimates of expected return and risk and past price correlation, which we shall see were improbably imprecise at the time. A great deal of work after these groundbreaking studies concentrated on removing the imprecision of variation in future returns, that is, risk.

Through a quirk of history, Treynor, by virtue of his unpublished early work in 1961 and 1962, is considered by some as the true originator of the CAPM, originally thought to have been Sharpe. ${ }^{9}$ Treynor puzzled over the enormous changes in present value when applying small changes to the discount rate for long-period cash-flow models. He understood that discount rates reflect risk, but how? This led to work on assumptions on asset valuations and risk, showing they worked in parallel to determine asset pricing. This important early contribution dovetailed perfectly with the Markowitz mean-variance optimization, which puts substantial emphasis on expected future asset returns and the "riskiness" of assets, that is, their probability of returns in the future. ${ }^{10}$

Jensen (1968) was the first to show that asset managers may not be efficient investors, that is, their "predictive ability" in finding securities or constructing portfolios that have superior performance to a benchmark is empirically absent (overall they delivered inferior, or at best neutral, investment returns). Jensen developed a method to explain outperformance or underperformance compared to a calculated expected return, resulting in the widely used "Jensen's Alpha" portfolio performance measurement: Jensen's Alpha = Expected Portfolio Return - (Risk-Free Rate + Beta of the Portfolio $\times($ Expected Market Return - Risk-Free Rate)). This nifty formula, built on the foundations of CAPM, has been subsequently critiqued, but survives as a common measure of portfolio performance in the global asset management industry.

For markets to achieve homogeneous expectations, one must assume that investors have rational expectations. Rational and homogeneous expectations themselves require an instantaneous distribution of information to investors. 
Under conditions of universal information distribution, market prices will adjust immediately to new information and achieve "fair value" as described by the risk adjustment factors of CAPM. The Efficient Markets Hypothesis (EMH), developed by Fama (1970), provided insight on the determination of market prices, that is, there are mechanisms that efficiently distribute information (in normal circumstances) to market participants such that a market may be deemed efficient (which is required for investors to make rational choices). Later behavioral finance research indicates there are inherent weaknesses in EMH caused by the often irrational choices made by investors, yet EMH continues to support Jensen's premise that "you can't beat the market" without adding risk equal to or greater than the additional expected return.

While not complete, the citations above encompass some of the major foundation work on MPT. There are, of course, many more contributors, not to mention Lintner, Black, Fabozzi, Elton and Gruber, and more from the likes of Markowitz, Treynor, Jensen and Fama (three of the five cited were awarded Nobel Prizes in economics). One can almost picture the fundamental theoretical research defining the boundaries of MPT lasting through to 1970, and its evolution as a practical tool for asset managers thereafter.

By the 1980s the concept of asset diversification and the application of basic MPT strategies were well established in the asset management industry, but there were still many more insights to come. Brinson, Hood and Beebower (1986) gave the industry its first look at what became known as attribution analysis. Portfolio performance was defined as a result of three subsets of activity: the investment policy defining the composition and weight of investing in each available asset category (the "Policy Portfolio"), the timing of overweighting or underweighting allocations in each asset category (such variation compared to the Policy Portfolio) and the selection of securities within each asset category, all as measured by the R squared of the regression of each examined fund's returns. Not surprisingly, given the Efficient Markets Hypothesis, investment policy was shown to contribute $90 \%$ or more of a portfolio's return variation, marginalizing the impact of timing and security selection. The article's topic became known as BHB (after the names of the authors), and sparked a lively debate in the industry as many managers naturally wish to extol the virtues of their trading prowess, an activity that requires precision security selection and market timing, but found BHB shadowing their hubris. Because BHB argued that variations in return were almost entirely due to top-down policy and not trading strategies, the industry shifted toward emphasis on macro asset allocation, while traders still fought hard for their turf.

Black and Litterman (1992) considered CAPM equilibrium portfolio modeling on a global scale, in multiple asset categories (further consolidating multi-asset-class investing's legitimacy). Considering the availability today 
of fine-grain data and analytics from nearly every market, their assumptions on the poor quality of data (leading to unconvincing or no investor views of expected returns in other markets) in the early 1990s seem quaint. They combine key ingredients of MPT, the Markowitz mean-variance optimization and the Sharpe (or Treynor) CAPM. Black and Litterman (1992) explained the extreme sensitivity portfolio asset class weights have to expected return assumptions, and the investor's conundrum in weighting portfolios where no or weak views of expected return exist. They allowed for a model that creates a global equilibrium risk benchmark, from which investors can express their views, both weak and strong (or neutral), in all, few or no markets. The key is adding probability weights to those views.

Jorion (1992, p. 68) may have been somewhat obscure, but expressed a view that resonates powerfully in the context of the application of MPT to sharia-compliant assets today: "Given the wide applicability of the mean variance paradigm, it seems astonishing that investment practitioners do not put it to use more often." Jorion (1992) highlights estimation risk, the possibility that inputs such as expected returns, risks and correlations may be faulty (going back to Treynor's observed large variations in present value when discount rates are lightly altered). To overcome this handicap, Jorion (1992) introduces "fuzzy" data, meaning dispersion ranges around a benchmark instead of absolute numbers for mean-variance optimization inputs. By using dispersion methods as an input in global portfolio allocations, Jorion indicates the superiority of international diversification. ${ }^{11}$

Lummer and Reipe $(1994)^{12}$ remind us that all security selection decisions are preceded by asset allocation decisions, meaning decisions are made on the weights in each category of a portfolio before the decisions on the composition of securities inside those categories. They also remind us that as early as the beginning of the 1970s - a time when many professional asset managers still did not understand the utility of Markowitz (1952) - many investors knew that diversification was essential to risk management, but simply allocated according to common sense, not through statistical interpretations of expected returns and risks. The utility of Lummer and Reipe (1994) lies in their summary of then-common methods of portfolio allocation, methods that have essentially survived intact since. Amusingly, they remark that in 1994, more than a quarter century ago, investors were just beginning to appreciate global investing and multiple asset categories. They also observed the increased utility of MPT when applied to asset categories, and not simply securities within a category, something perhaps taken for granted today. Importantly for this discussion, Lummer and Reipe (1994) highlighted the ability to utilize MPT in a continuous dynamic fashion, replacing call options with risk-free cash positions and adjusting portfolios to immunize them from downside risk. Given the availability of risk-free cash substitutes in the Islamic economy 
(i.e., high-credit-quality Islamic bank deposits, for example), this gives rise to a potential dynamic asset allocation model that would be sharia compliant.

By the 1990s, MPT, and the general acceptance of diversifying multi-asset-class portfolios based on correlation, was a mature, well-established practice among asset management professionals. MPT had extended itself from the rare application among a few U.S. equities, to a broad application among global asset categories, and even in non-financial industries, for example electricity distribution and mobile phone tower load management. While legitimate concerns were raised, in particular on rational behavior and measures of expectations, the 1990s witnessed the global adoption of MPT as the core technique to invest one's own or a client's assets.

Elton and Gruber (1997) celebrated this maturing investment process with a seminal piece highlighting the achievements of MPT, as well as some of its idiosyncrasies. Most notably they confirm the persistence of MPT despite well-founded doubts and suspicions of its utility. It is intuitive, after all. Elton and Gruber's snapshot of MPT at that time included confirmation of the utility of mean-variance portfolio theory, showing how it evolved to answer to multiple periods, that is, that MPT could be adjusted at intervals to adapt to new information. Their second point indicated that accuracy problems once associated with data collection were largely a thing of the past due to higher computational speeds, but also because the use of index models substantially reduced the number of calculations. Their third focus indicated that future applications of MPT will finally add liabilities, a complexity considering the combined uncertainty of both investment returns and liability cash obligations (e.g., insurance companies and pension funds). They conclude with a look at portfolio evaluation to justify the value added by portfolio managers (i.e., in the vein of BHB). Without going into their detailed discussions, they show Jensen's Alpha and the generalized Sharpe ratio are still relevant methods of determining portfolio performance against an index, in the process debunking continuing myths regarding added returns from investment timing.

Soon after Elton and Gruber (1997) the work of Fabozzi, Gupta and Markowitz (2002) arrived to celebrate the 50th anniversary of the article "Portfolio Selection" (Markowitz, 1952). In the course of five decades, MPT had transformed investment management, primarily because professional managers now had the tools that didn't exist in previous generations. Like Elton and Gruber (1997), the authors surveyed the breadth and depth of MPT applications, importantly including the increasingly frequent use of MPT for macro asset allocation decisions, that is, choosing asset category weightings. Importantly, they take head-on the subject of historic data leading to misleading optimized portfolios. Despite an industry praying for tools to remove uncertainty, there is still a large component of human judgment and reasoning required in creating a set of expected returns. There is no magic bullet, or 
not yet. They conclude by noting innovative applications of MPT, including risk-of-loss analysis, multifactor risk modeling, Value at Risk management and risk budgeting. All these innovations are commonplace in the industry now, supported by abundant literature in each category.

Again on the decomposition of portfolio performance, Berk $(2005)^{13}$ starts with a repetition of criticism of highly paid portfolio managers never persistently beating market indexes, leading one to ask, what value do they add? By this point in asset management history the industry is global and well established, and with tens of trillions of dollars under management it does not in a practical (not theoretical) sense need justification. Berk (2005) says criticism of investment managers is based on myth, explaining that scale is important. Rational and informed investors will seek the best manager until his Alpha (returns above the risk premium, without the premium risk!) is exhausted by too much money to manage. Investors will seek the second, then the third, and then the Nth manager until all have exhausted their above-average expected returns simply due to problems of scale. Returns from managers sink until they reach index returns. Conversely, underperforming managers will lose clients and AUM, increasing their ability to increase performance. In both cases both under- and overperformers will be pushed toward the market index return. But are asset managers skilled (versus simple index investing)? Using indirect measurements, plotting management skill on an axis and showing the distribution of after-fee returns from managers, Berk (2005) shows that $80 \%$ of all managers contribute positive after-fee Alpha!

In support of managers contributing Alpha (portfolio outperformance above an assigned benchmark), Alankar, Blaustein and Scholes (2013) posit that investor constraints on managers result in less-than-optimal portfolios, which will result in masking the manager's true Alpha performance. Here the well-known practice of imposing tracking error (where managers are rated according to their ability to perform at or above benchmark returns) and liquidity reserves (to manage costs and redemptions) essentially creates two portfolios, one for Alpha-generating investments and the other to manage the costs of the constraints. Alankar, Blaustein and Scholes (2013) explain that when the performance drag of these costs are removed, or if the performance of the manager is examined in isolation of these costs, there is actually the possibility that Alpha is being generated.

Perhaps at this point it is useful to digress from scholarly literature, and look to the trade. While not peer reviewed, many trade publications reflect the implementation of decades of scholarship. It's not an accident that professional asset managers, few of whom are scholars, follow the guidelines laid down by Markowitz, Tobin, Treynor/Sharp, Jensen, Fama and Black. Chief investment officers mostly have at least Master's degrees in related fields, and presumably most of those have read Elton and Gruber's Modern Portfolio Theory and 
Investment Analysis in graduate school, considered the foundation educational text for asset allocation.

Gibson (2007) and Idzorek (2010) ${ }^{14}$ are typical of this genre. Both were published by industry leaders, the former (MFS Investment Management) an asset manager with nearly $\$ 500$ billion in AUM, the latter (Morningstar) a market analytics and data provider, tracking tens of trillions of dollars in mutual fund AUM. Both extol the virtues of MPT as the core of asset allocation, written in a style for the educated layman. In simplified language, the first describes the diversification benefits of Markowitz's mean-variance optimization and emphasizes the importance of multiple asset categories in asset allocation. Gibson (2007) charts real-world portfolios comprising multiple asset classes, indicating their superior risk-return characteristics. Idzorek (2010) is in fact a scholarly article embedded in a trade publication. It returns to Brinson, Hood and Beebower (1986) and the BHB controversy, where laymen quickly assumed that portfolio total return and not portfolio return variance was $90 \%$ or greater controlled by macro-policy investment decisions. In fact, he shows $100 \%$ or more of total return is due to investment policy (i.e., portfolio weightings by asset category), and that timing and security selection were in fact a drag on performance. By identifying errors in methodology, Idzorek (2010) reconfirms the basic principle of "asset allocation is king."

By the late 2000s a new asset management strategy emerged, particularly where investment managers began using quantitative signals to more actively time over- and under-weighting asset categories. Herold et al. (2007) looked at multi-asset-category portfolios and dynamic asset allocation, all in the context of institutional investors seeking to minimize downside risk in a low-yield environment (an environment that persists today). Interestingly, while concepts such as risk budgeting and Value at Risk were unheard of during the early days of Markowitz, and even Sharpe and Treynor, by 2007 they had become hugely influential in managing large, complex portfolios for institutional clients. Passive management was becoming a thing of the past. However, the relevance of options as used in this strategy is null for sharia-compliant investors, meaning the portfolio insurance required for this strategy is not applicable in the Islamic asset management space. Despite this, the study indicates several important achievements in asset management and portfolio diversification: by now dynamic asset management has attained respected credentials.

This section closes with summaries of two intriguing works, Ibbotson (2010) and Doeswijk, Lam and Swinkels (2014), that help us understand the theoretical underpinnings of MPT. Again, these were selected from among hundreds of contemporary relevant works on global asset allocation. They represent a class of literature that validates and continues the basic premise of MPT and the fundamental utility investors seek in globally allocated, multi-asset-class portfolios. 
Ibbotson (2010), a commanding presence in scholarly work on asset allocation, is also a well-known asset management industry professional. With over 15,000 citations, his frequent treatment of Efficient Frontier investing stretches back more than 40 years. Ibbotson (2010) addresses the by-then well-studied subject of attribution analysis, answering the common investor question: "Where did my performance come from?" Since Brinson, Hood and Beebower (1986), a large body of work - principally called attribution analysis - has tried to answer this question. There was a great deal of emphasis, and not a shortage of misinterpretation, of the BHB proposal that over $90 \%$ of portfolio return variation derives from top-down policy decisions. Ibbotson (2010) subsequently questions that result, showing in fact that $100 \%$ of return is derived from policy, while only about $40 \%$ of return variation is so ascribed. He further clarifies that we have to be more specific in decomposing a portfolio manager's returns. In the global financial crisis of 2008, for example, the prices of nearly all assets declined, and by 2010 everything went up, essentially independent of manager decisions. Market factors impacting asset category valuations explain a great deal of portfolio return variations, while policy, timing and selection comprise the balance.

Perhaps this focus on decomposing returns may seem overemphasized. But to some degree it's what also drives the markets, or more accurately the competition between managers for investor funds. Every manager likes to boast about his returns, showing outperformance compared to benchmarks. But how did he or she achieve those returns? Finding out is critical to the industry's ability to convey its value to investors. At the heart of this argument is the role, and now clearly obvious value, of asset diversification and manager's active role in selecting a portfolio of diversified securities.

Doeswijk, Lam and Swinkels (2014) contains an important summary of the world's capital markets, supported by financial market data going back to the 1950s. Here the authors sum up exactly what's out there-the securities that investors can actually buy, whether they are stocks, bonds, hedge funds, commodities or even private equity. They start with Tobin's (1958) fundamental assessment that all assets are tradable and observable in the markets, and the subsequent realization via the CAPM that every investor must diversify investments between risky and riskless assets. They then proceed to refine the argument toward true global market investing, and a definition of the global market portfolio. How can one honestly achieve a global market portfolio if the nature and extent of global markets are unknown? (They state that their global capital market survey is the first ever study of its kind.) Doeswijk, Lam and Swinkels (2014) conclude there is an $\$ 85$ trillion worldwide securities market, indicating for the first time the detailed composition of that market. For globally diversified investors, here is an indication of just how they can construct a universal benchmark. Importantly, they delineate the precise components 
of that global market, from government and corporate bonds, to equites and commodities, and real estate and hedge funds. What is not surprising is that the emerging Alternative Investment asset class, while growing steadily in size, remains trivial, despite its overwhelming presence in popular media (e.g., private equity, hedge funds and real estate). In a way, Doeswijk, Lam and Swinkels (2014) performed for the conventional asset universe what this author hopes to perform for the sharia-compliant investible universe, albeit only among Islamic mutual funds and ETFs.

\section{A BRIEF DISCOURSE ON CAPM AND SHARIA}

Many readers are aware of a fundamental principle of Islamic finance, the well-known prohibition against riba, or interest. It is useful to mention that there are various forms of prohibitions in sharia, for example pork, alcohol and gambling. Another is riba (or, earning money on money). Among the various activities considered haram - or forbidden - in Islam, one of the strongest prohibitions is against riba, so it is natural that some persons might wonder about riba in the context of the CAPM.

The core of this study is not intended to examine the sharia aspects of CAPM. Rather, it is intended to examine how the existing universe of sharia-compliant investment securities can be used in the context of the industry-standard methodologies of optimized asset allocation that is based on MPT, or MPT. In other words, it accepts CAPM as a significant and important component of portfolio optimization that, on the surface at least, is acceptable to Muslims and, in the context of industry application of CAPM, required for apples-to-apples comparisons between sharia-compliant and conventional (non-Islamic) portfolios.

Thankfully, the sharia aspects of CAPM have been dealt with elsewhere by sharia and academic scholars and-as is further discussed below-are of minor or no concern in this study except perhaps as a side note to discuss contemporary and historic scholarly discussion on how Muslims see the risk-free rate and adapt to it or change it for sharia compatibility. In fact, this study should be able to stand alone with no mention of an Islamic CAPM (ICAPM). In other words, an ICAPM is a peripheral and not central issue to this study and, as indicated below, to academic scholarship to date on Islamic investing.

Again, the intent here is to see whether contemporary asset management professionals can construct Islamic portfolios using the existing universe of sharia-compliant products and the contemporary tools of asset management, all within the context of the theoretical constructs that support MPT. Perhaps other scholars may wish to discover and apply an ICAPM in this context, but for the moment it is outside the scope of this book.

The expected utility of this book is that it is real time, real world, that is, it attempts to solve an important problem faced in the global \$100 trillion asset 
management industry, where at least some Muslim clients who care about sharia may desire sharia-compliant, multi-asset, optimized portfolio investing services from their asset manager but cannot find these services anywhere. This by itself does not automatically invalidate the theoretical underpinnings of MPT because it may or may not be sharia compliant. In other words, it's the output that is important, not the input. A treatise on an ICAPM is not relevant to the core effort attempted here.

\section{The Concept of Ijtihad}

Islam and finance have a long and detailed history. The earliest sayings and writings from and about the Prophet Mohammed ${ }^{15}$ included discussion of various types of then-common business agreements between economic actors. However, in modern times new forms of finance arose. These included financial transactions that were unheard of during the life of the Prophet. Those who more recently sought a modern system of Islamic finance discovered no direct parallels for modern interpretation of historic texts, for example there were no treasury bonds, derivatives or equity warrants issued in the seventh century.

In order to create some sort of order, the Islamic jurisprudence community began over 30 years ago to organize their thinking on financial contracts, which ultimately are at the heart of any financial security. Here they were forced to make analogies from seventh-century events and apply those analogies to contemporary times in order to create modern solutions. The process is called ijtihad, which essentially translates to physical or mental effort, but in this case means the effort to find contemporary solutions based on centuries-old proclamations of right and wrong. Ijtihad is defined in Islamic finance as, "the process of deriving [sharia] rules for ... new incidents from ... [sharia] sources" (Abdulazeem, 2016).

What this means is that Islamic finance is an ongoing effort to find contemporary financial intermediation solutions based on the foundation knowledge of sharia. Ijtihad also means a "struggle" to achieve perfection, but knowing in the process that there are times when perfection cannot be immediately achieved. Muslim scholars accept that we are in a process of creating the "perfect" environment for Islamic finance, but that the concept of "perfect" is still a long way off. In the meantime, imperfect solutions are accepted (as long as the intermediate solutions themselves improve the status quo), until such a time that they can be perfected.

This is the case with much of contemporary Islamic finance. Because it is widely acknowledged to be a process, it is also widely accepted that it is imperfect today. If one accepts ijtihad, which says that one must at least "struggle" (or make an effort) to improve, then the current conditions are acceptable until better ones are available. 
How is this relevant to an ICAPM? As discussed below, Islamic scholars acknowledge that many or most Muslims live within an interest rate environment. They accept that there is no perfect Islamic economy anywhere on the planet. As such, they accept that any advance in the direction of an Islamic economy is better than no advance at all, no matter how imperfect that advance may be. In other words, until there is widespread acceptance for a replacement of CAPM, there will likely be no curtailing of Islamic asset management solely because of the lack of an ICAPM. ${ }^{16}$

\section{An Islamic CAPM}

From all the available evidence, CAPM is neither philosophically nor theologically rejected on any widespread basis in the practical application of Islamic finance. While the evidence is sparse, the embedded risk-free rate of CAPM has periodically been dealt with in Islamic finance, and both Islamic finance and religious scholarship have occasionally examined CAPM and its utility.

Selim (2008) was perhaps the first scholar to decompose the components of CAPM and explain which elements may not be sharia compliant. While he did not address short sales, he did posit that Islamic financial contracts must be based on profit-and-loss sharing. Whereas Sadaf and Andleeb (2014) suggest the risk-free rate can be substituted with the relevant rate of inflation (stating, somewhat incoherently, that the Islamic state must guarantee the purchasing power of wealth), Selim (2008) inserts a risk-free rate of zero, indicating zero is the optimal point for the risk-free rate in risk-sharing partnerships. Unfortunately, Selim (2008) suffers from a focus entirely on musharakah contracts, akin to private equity or venture capital investing in conventional markets. Its applicability to portfolio investing of the kind mostly practiced in global asset management is highly limited.

Farooq (2014) acknowledges the quandary of using interest-based analytical tools when trying to understand concepts in Islamic finance. He states that the

Conventional financial system is based on an interest rate structure, as for example in [the] CAPM, where the base of this model is an imaginary, but fixed risk-free, real rate of return. Combined with inflation premium it is regarded [as] equivalent to the return on 3-month US Treasury Bills. Then, various risk-premiums are added to price various financial products. Based on [the] orthodox Islamic position, such structures are un-Islamic because there is [a] fixed and stipulated rate of return involved.

But Farooq (2014) goes on to explain that the Islamic finance system "would be unable to function without the global conventional market providing an interest-based structure." This segues well to the concept of ijtihad. Islamic finance practitioners accept that they operate in an environment of 
interest-based structures, and must adapt to it. Further, Farooq (2014) argues that criticism of this arrangement is hollow unless and until critics are able to deliver acceptable, practical solutions, that is, the eventual perfection that is sought in ijtihad. In short, we live in an imperfect world, and must accept certain conditions that are less than ideal.

There are a few absolutists in Islamic jurisprudence who believe that no compromise is possible. Hardliners exist in every community, it seems. Fortunately, they are vastly outnumbered by Islamic scholars who accept flexibility and accommodation. ${ }^{17}$ In the words of Sheikh Yusuf DeLorenzo, a noted and respected sharia scholar in Islamic finance:

A benchmark is no more than a number, and therefore non-objectionable from a sharia perspective. If it is used to determine the rate of repayment on a loan, then it is the interest-bearing loan that will be haram. LIBOR [or, U.S. Treasuries] as a mere benchmark has nothing to do with actual transaction or, more specifically with the creation of revenue or return. ${ }^{18}$

So, too, with using U.S. Treasuries as a proxy for the risk-free rate. If it's just a number, and if the overall structure of the mathematical formulation is not in violation of sharia, then as implied by such a noted sharia finance scholar such as Sheikh Yusuf, using U.S. Treasuries as the risk-free rate would not by itself violate sharia. Since the risk-free rate is simply a concept of the cost of capital where there is no risk, and is not an absolute (while very low in risk, U.S. Treasuries have more than zero), then the concept can be substituted with a proxy such as U.S. Treasuries, just as LIBOR is used to price sharia-compliant loans because when a loan is deemed sharia compliant there is no prohibition in using LIBOR as a proxy for the price of capital.

One might state that CAPM (and therefore MPT) is not compatible with sharia because, "riba (interest) is against sharia, and CAPM requires a risk-free rate, which means interest, which means CAPM is against the fundamental beliefs of Muslims." This chain of logic is clear, and rationalized by persons not familiar with the concepts and practice of contemporary Islamic finance. However, there are two problems with this conclusion. First, it ignores the fact that CAPM has already been examined by sharia scholars, and second that the use of CAPM does not by itself invalidate optimized portfolio constructions because the risk-free rate is a concept, not an absolute. Like the use of LIBOR in Islamic loans, proxies (such as U.S. Treasuries) for the risk-free rate do not invalidate CAPM. Muslims certainly do not argue that capital does not have a cost, so therefore they will not in general argue against using common measures for the cost of capital.

Regarding the first problem, one can thankfully find a risk-free rate in the Muslim world acceptable to sharia scholars. The easiest is to look at 
government-issued sukuk (e.g., sukuk - also called Islamic bonds - issued by the governments of the U.K., Luxembourg, South Africa, Saudi Arabia, etc.) or lending rates between Islamic bank treasuries, which has been well treated by Nechi and Smaoui (2018) in their discussion of the construction and operation by Thomson Reuters of the Islamic Interbank Benchmark Rate (IIBR). In other words, few if any scholars on Islamic investing will discard CAPM because of an absence of a risk-free rate, when ready substitutes acceptable to Islamic scholars are available.

Hazny, Hasim and Yusof (2020) are the most recent of several academic scholars who have drilled down into CAPM in an effort to establish an ICAPM. Only two significant issues arise. The first, of course, is the risk-free rate, but that problem is easily dismissed by using a commonly available Islamic risk-free rate as mentioned above. The second is more problematic as it involves the concept of unlimited short sales (under sharia one cannot sell an asset that one does not already own). Here Hazny, Hasim and Yusof (2020) simply advocate the removal of short sales from the mathematical modeling of ICAPM, which has no significant impact on the resulting optimization tool. Importantly, Hazny, Hasim and Yusof (2020) point out, “... the traditional CAPM is a relevant model in Islamic finance. Most of the assumptions underlying the Markowitz's Mean-Variance Portfolio Theory are not contradictory to shariah principles."

As indicated above, one can extend this discussion to the parallel and nearly universal use of LIBOR (and other interbank offer rates, such as Saudi Arabia's SIBOR) as the pricing basis for Islamic fixed income securities and lending. Rather than expending considerable time on the scholarly treatment of LIBOR in Islamic finance, I simply refer to a quotation from one of the most respected names in contemporary Islamic finance, Sheikh Mohammad Taqi Usmani:

No doubt, the use of the rate of interest for determining a halal profit cannot be considered desirable. It certainly makes the transaction resemble an interest-based financing, at least in appearance, and keeping in view the severity of prohibition of interest, even this apparent resemblance should be avoided as far as possible. But one should not ignore the fact that the most important requirement for validity of Murabahah is that it is a genuine sale with all its ingredients and necessary consequences. If a Murabahah transaction fulfills all the conditions enumerated in this chapter, merely using the interest rate as a benchmark for determining the profit of Murabahah does not render the transaction as invalid, haram or prohibited, because the deal itself does not contain interest. The rate of interest has been used only as an indicator or as a benchmark. ${ }^{19}$

To repeat the concept expressed by Sheikh Yusuf DeLorenzo: one does not need to eliminate interest rate measures in Islamic finance simply because the 
measures are derived from interest rates. The utility of interest rate measures has long been accepted in Islamic finance where the overlying and underlying structures are sharia acceptable. Measures based on interest rates are convenient tools for measuring the cost of capital, which is fully acceptable in Islamic finance.

Because the securities selected for the optimized Islamic portfolios ultimately used in this study are fully sharia compliant (all carry fatwa that are widely recognized by sharia scholars), the use of CAPM is not by itself an egregious violation of sharia. Yes, one could reconstruct the entire book by using an ICAPM that embeds an adjusted common sharia-compliant risk-free rate such as Saudi government sukuk or Saudi interbank offer rates, but since those numbers would be nearly identical to U.S. Treasuries then what would be the point? The outcome would be the same.

Let's take a quick look at the literature that relates, even tangentially, to Islamic asset management. If CAPM is commonly and historically used by an overwhelming number of academic scholars as a measure in analyzing security, index or portfolio performance in the context of sharia-compliant investing, then perhaps one may consider that academic scholars do not have grave concerns over the utility of CAPM in analyzing Islamic assets; nor do they find any specific need to separately develop an ICAPM. We summarize a few important papers herewith, but we benefited from a number of papers written by the co-authors that we include in the book's Further Reading section.

- Naqvi et al. (2018): “... we employ several statistical measures starting from the Jensen's Alpha and an extended CAPM-inspired-market-model ..."

- Rahim and Ahmad (2016): "Thus, there were no surprising results, although this study was tested with the extended CAPM, including data of KLIBOR and government Sukuk yield."

- Kamil et al. (2014): "Three common models of alpha computation will be adopted, namely: i. As per CAPM described in Sharpe (1964) and Lintner (1965) ..."

- Al-Khazali, Lean and Samet (2014): "In our paper, we present the CAPM statistics of Islamic and conventional Dow Jones indexes for different countries and regions over a long time period (1996-2012)."

- Ashraf (2014): "The basic model to measure the relative performance of IEIs [Islamic Equity Indexes] is within the context of the standard CAPM ..."

- Ho et al. (2014): “The generalized Capital Asset Pricing Model (CAPM) regression model is applied to determine the beta of the individual index with the market index." 
- Kassim and Kamil (2012): "The returns on the unit trust funds are obtained from income and ... capital gain. The rate of returns for each fund is calculated as follows: ... The Jensen Index or alpha was developed by Jensen (1968) based on the capital asset pricing model (CAPM)."

- Tahir and Brimble (2011): "Systematic risk is defined in terms of the traditional CAPM beta calculated with the market model ..."

- Hoepner, Rammal and Rezec (2011): "We present and discuss our results in order of increasing sophistication of our econometric model. We start with the capital asset pricing model (CAPM) and Carhart model and proceed to the unconditional and conditional three-level Carhart model."

- Hayat and Kraeussl (2011): "We estimate the risk-adjusted performance (alpha) and systematic risk (beta) for each IEF [Islamic Equity Fund] using Jensen's (1968) version of the capital asset pricing model (CAPM)."

- Merdad, Hassan and Alhenawi (2010): “Jensen's alpha was first used by Michael Jensen in the 1970 s as a measure to evaluate the mutual fund manager's performance. It is conventionally used to determine the excess return of a security (or portfolio) over the security's theoretical expected return or risk adjusted return predicted by a capital asset pricing model (CAPM). In this paper, Jensen's alpha is the coefficient of the constant term in equation (4) mentioned above. A positive and significant alpha indicates that the manger has superior selectivity skills."

More examples can be provided, but perhaps the point is clear. Contemporary academic literature on Islamic investing nearly universally does not concern itself with an ICAPM. In fact, little of the literature cited here and in the literature review rejects CAPM in any form. CAPM is the basis from which most contemporary scholarship extracts analysis on sharia-compliant investing.

In other words, CAPM as it stands appears to work fine for nearly all analysis of Islamic finance, whether in academic or religious scholarship. Questions of a riba component of the risk-free rate appears to have no influence on academic scholarship on Islamic investing.

Here we detour for a short discussion of Hakim, Hamid and Meera (2016) and Pristiwati and Widianingsih (2019). These academic scholars fall into the (observably small minority) school of thought that generally opposes CAPM as a common measurement tool for sharia investing. Hakim, Hamid and Meera (2016) argue that Islamic investments are a subset of all investments, so therefore the market portfolio of CAPM is by nature unsuited for comparing the market portfolio of an ICAPM (i.e., the broader CAPM market portfolio contains securities that are not sharia compliant). The authors created two substitute ICAPMs and tested them against market portfolios (sharia-compliant equities) in the Malaysian stock exchange. They use an AAA-rated Malaysian sukuk yield as their risk-free rate. They concluded that both their ICAPM 
and CAPM were identical over longer terms in explaining portfolio returns. In other words, while there are scholars who can argue against using CAPM in measuring sharia-compliant portfolios, in practice Hakim, Hamid and Meera (2016) indicate there is no difference between ICAPM and CAPM in real-world investing.

Similar conclusions were obtained using a different methodology to construct an ICAPM (or, as the authors note, an SCAPM, or sharia-compliant CAPM) in Pristiwati and Widianingsih (2019). Here the authors declare the sharia incompatibility of CAPM due to short sales, but importantly a reliance on those sales via a risk-free rate, which they claim is fundamentally in violation of sharia. They construct three new ICAPMs, where the traditional risk-free rate is substituted with three different rates: (1) none at all, (2) the zakat (Islamic asset tax) rate, and (3) the relevant government sukuk rate. In all three cases they indicate no relevant difference in the ultimate measure of return.

The research in this study was conducted to provide a solution to asset managers who may have Muslim customers desiring sharia-compliant investing, where the solution is fully grounded in contemporary academic theory. As will be seen in Chapter 4, this study did so by first identifying the sharia-compliant investible universe, then filtering that universe so that it meets contemporary institutional standards, resulting in a Buy List that could be then subjected to MPT allocation methodologies. At no point did this study question the validity of CAPM in the context of sharia because at no point was that considered relevant or necessary. Note the highlighted phrase in the Research Question: "What are the performance (and risk) characteristics of multi-asset optimized portfolios comprising sharia-compliant securities as measured by contemporary risk and reward metrics, and how does this performance compare to conventional (non-Islamic) peer portfolios that are equally constructed?" Here "contemporary risk and reward metrics" is emphasized because this study concentrates on those contemporary tools used by professional asset managers today, all derived from CAPM. This study did not state that this would be done using new metrics based on an ICAPM, which is entirely outside the scope of the work in this book.

Again, this study is not about creating an ICAPM. The bodies of Islamic and academic scholarship apparently do not believe this is needed. Yes, scholars have from time to time deconstructed CAPM to see where it may violate sharia, but until now there has been no body of sharia scholarship that categorically rejects CAPM as an optimization tool for Muslims. And, as mentioned above, one can reconstruct CAPM theoretically to eliminate the short sale component (but not remove the fundamental concept of risk-free rate, which is not necessary) but there is apparently no practical difference in doing so, and 
there is no utility for the global asset management industry. It seems that the construction of an ICAPM is simply unnecessary.

This discussion of the ICAPM closes with an important point on methodology. One might ask that an ICAPM be constructed so that subsequent Islamic portfolio construction and performance (risk and return) can meet a more fundamental concept of sharia acceptance.

However, even if such an ICAPM was constructed, what then? Would we then compare the results of Islamic portfolios to conventional, non-Islamic portfolios constructed using conventional CAPM? Are we not entering an "apples and oranges" argument? The core concept of this study was to subject sharia-compliant assets to one set of rules in portfolio allocation for a particular investment strategy, then compare that portfolio to an equally constructed conventional peer.

In other words, how would one compare an automobile built under Earth-based safety regulations to an automobile built under Martian safety regulations? They would be fundamentally incompatible for comparison. If a study of the performance and risk of two separate portfolios is going to be conducted, where only the ingredients of the portfolios differ, then the construction methodologies and processes of building those portfolios must be identical; they must follow the same rules, that is, they must adhere to the same theoretical constructs. There is no other way to make valid comparisons without fundamental contradictions.

Further, this book attempts to discover whether industry-practical solutions are available. No one can anticipate the entire global asset management industry abandoning their Bloomberg terminals, or ditching the myriad optimization software programs available to portfolio managers. Since the measurement difference between CAPM and an ICAPM has been shown to be essentially negligible, it makes the utmost sense to use CAPM in this study, as is evidently nearly universally common in academic scholarship to date.

This book makes an effort to achieve this. It constructs optimized portfolios using sharia-compliant securities, then it compares the results of the Islamic portfolios to identically constructed conventional, non-Islamic portfolios. In both cases, MPT, with its embedded reliance on CAPM, is used in the optimization processes. Professional asset managers should find utility in that because they may seek to replicate this process in-house and provide something that does not yet exist: multi-asset, optimized portfolio investing that uses sharia-compliant securities. If one disregards the argument that CAPM violates sharia, then one could say the result is Islamic asset management. 


\section{ASSET ALLOCATION AND ASSET CATEGORIES}

Having grounded itself in theory, MPT needed to extend to the practical art of asset allocation. We declare now that until this point there have been no spiritual components yet identified in asset management, at least not visibly applicable to one or another religious identification. As mentioned, so far we can conclude that the theory of asset management is quite secular in nature. ${ }^{20}$ Here we'll show that the process of asset management is also by nature almost exclusively a secular activity.

"Asset allocation is a process and a result" (Maginn et al., 2007, p. 231). The process presumes that all necessary data on an investible universe is available, with price and other information available for all assets in every asset category. It requires first and foremost the identification of the strategic investment objectives of the investor. What is the investor's desired long-term return outcome, and what degree of risk is tolerated to hopefully achieve that outcome? The process begins by estimating future expected returns by asset category, both foreign and domestic, and then determining portfolio weights for each category. The result is a strategic asset allocation, or Policy Portfolio. Commonly, institutional investors of all kinds establish a Policy Portfoliocomprising weights by asset class-before concerning themselves with the securities that will be selected within each asset class of that portfolio.

Policy Portfolios - whether established by individuals or institutionsguide the subsequent asset allocation process. Over time the Policy Portfolio requires periodic updates and adjustments based on market expectations among and within asset categories, but the established bands between and within asset categories (e.g., between Fixed Income and Equities, and within Equities the choice of domestic versus international equities) generally are fixed for at least the short and medium term. This method of asset allocation is strategic in that the investor has made specific decisions that require long time periods for results to appear.

Changes made within this long time period are tactical in that they take advantage of what appears to the investor as short-term opportunities based on expectations of short-term market conditions. Tactical asset allocation, therefore, is a component of strategic asset allocation, but as a rule is not allowed to fundamentally alter the long-range Policy Portfolio.

At the heart of strategic asset allocation is the goal of achieving sufficient diversification to eliminate unsystematic risk, leaving the portfolio exposed only to that level of systematic risk desired by the investor. In other words, a sufficiently diversified portfolio containing assets across categories, and diversified within each category, subjects the portfolio only to those risks that cannot be diversified away. 
Investors seek investment goals that are quantifiable, for example to exceed the rate of inflation (preserve purchasing power), to provide adequate funds for retirement or inheritance, or to cover living costs or other cash obligations. At the same time, we can quantify the risk an investor accepts in achieving those investment goals by measuring the investor's aversion to investment return shortfalls or minimum acceptable downside. Each asset category will have its own expected return and risk profile. The investor will seek that portfolio of diversified assets that is optimized in terms of return and risk, that is, the magic point of optimality where one's Efficient Frontier is tangent to the Capital Market Line.

In both theory and practice, the riskiness of owning a single asset can be improved by adding a second asset that has a different historic price correlation. The same mean-variance optimization works across asset categories, so adding an additional asset category to an investor's portfolio can improve the portfolio subject to the new asset category's correlation to the original portfolio. Portfolios are constructed to achieve the optimal level of expected portfolio return considering the desired level of expected portfolio risk, or vice versa. As an example, consider the following hypothetical three portfolio options comprising four asset categories (Table 1.1).

Table 1.1 Hypothetical allocations among asset categories

\begin{tabular}{llllllll}
\hline Portfolio & $\begin{array}{l}\text { Expected } \\
\text { Return }\end{array}$ & $\begin{array}{l}\text { Standard } \\
\text { Deviation }\end{array}$ & $\begin{array}{l}\text { Sharpe } \\
\text { Ratio }\end{array}$ & Cash & Bonds & Stocks & Alternatives \\
\hline 1 & $6 \%$ & $5 \%$ & 0.70 & $5 \%$ & $55 \%$ & $25 \%$ & $15 \%$ \\
2 & $8 \%$ & $10 \%$ & 0.60 & $5 \%$ & $45 \%$ & $35 \%$ & $15 \%$ \\
3 & $10 \%$ & $15 \%$ & 0.50 & $5 \%$ & $35 \%$ & $45 \%$ & $15 \%$ \\
\hline
\end{tabular}

Source: Author's work.

Depending on his or her choices, the investor may select any of the above asset allocations. More risk-averse investors will seek those portfolios displaying lower standard deviation and higher Sharpe ratios (Portfolio 1), while more risk-tolerant investors will seek the opposite (Portfolio 3). In practice, most of us are somewhere in between (Portfolio 2).

Each asset class consists of securities that are homogeneous in that a security can fit into one basket of assets but not another, but also each class displays the ability to diversify the risk and returns when measured against other asset classes. As mentioned, common practice specifies these asset classes as Cash, Fixed Income, Equities and Alternative Investments, comprising respectively money market instruments, bonds, stocks and securities that do not fit into the previous three categories, that is, hedge funds, real estate funds, commodity 
funds and so on. By nature this includes all securities, both domestic and foreign to the investor.

To illustrate the discussion of asset allocation, it can be viewed as a linear progression of evaluation, data collection and methodology choices, followed by observation and feedback as shown in Figure 1.1. ${ }^{21}$

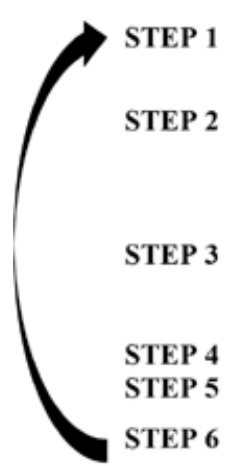

Figure 1.1
Investor evaluates global capital market conditions Investor creates expectations

for future market returns and risks

Investor combines expectations for market returns and risk with the investor's tolerance for risk using a portfolio optimizer, calculating that portfolio with risk and return optimized for the investor's return expectations and risk tolerance

Investor chooses an optimized portfolio allocation Investor observes results of optimized portfolio At end of each period the results are fed back into Step 1 of the subsequent period
Investor sums assets by categories

Investor measures risk tolerance

Initial and subsequent steps of asset allocation, with return to initial steps

Source: Author's work. Concept taken from Maginn et al. (2007).

\section{DISCUSSION OF MARKET DATA SOURCES AND USES}

The above section sought to simplify the process of asset allocation and the determination of asset categories. However, none of the inputs for asset allocation and portfolio optimization can be realized without underlying market data. Over the past decades numerous data sources have sprung up, of which the most popular today in the investment management industry are Thomson Reuters, ${ }^{22}$ Bloomberg and, for those concentrating on mutual funds, Morningstar and Lipper (a unit of Thomson Reuters). Global spending on these data sources reached over \$28 billion in 2017, with Reuters and Bloomberg together accounting for nearly $60 \%$ of the global financial data market supply business. ${ }^{23}$

These services are ubiquitous in asset management. No asset management is conducted anywhere without the vast flow of data that allows for the measurement of one portfolio of assets against another. Bond funds, stock funds, hedge funds and just about every other type of investment management possible are entirely supported by the provision of data from one or more of the major data companies. 
Price history is required for mean-variance optimization, but far more information is required for filtering and sorting an investible universe. As is further described in the next chapter, "prudent man" regulations are ubiquitous, limiting the investible universe to only those securities considered acceptable to regulators and to professional common sense. In this context a data source must provide not only price histories, but also qualitative information such as the legal domicile of a security and the name of the exchange on which it may be bought (or whether the security is bought and sold over the counter), as well as further information for collective investment schemes (i.e., mutual funds) such as the name, address and domicile of the fund management company, the amount of AUM, the date the fund was launched, the name of the fund manager and liquidity provisions embedded in the fund prospectus.

Because of the immature nature of the Islamic asset management industry, there is yet no perfect data source. A cursory examination of the three major services shows Reuters and Bloomberg to have more extensive coverage of the sharia-compliant asset universe than Morningstar or Lipper. Due to familiarity and a perception of more in-depth information, we have chosen Bloomberg for analysis of the Islamic mutual funds industry. Morningstar only covers approximately 250 securities of the sharia-compliant investible universe, whereas both Bloomberg and Reuters have over 1,000, but with multiple duplicates that reduce the utility for data observation and analysis. While Morningstar has an unquestionable reputation for analysis of mutual funds generally, its coverage of the Islamic investible universe is limited in number and therefore presumably not useful for either professional use or this study.

Importantly, Bloomberg provides a relatively data-rich environment for Islamic asset management. It provides information on a fund, the fund manager and its legal domiciliation, as well as reliable price histories. Further, Bloomberg has advanced asset allocation tools that includes portfolio optimization modules, along with dozens of metrics with which to measure portfolio risk and return. For all these reasons Bloomberg is selected as the unique data source for this study. However, further research could repeat the steps below using Reuters to insure there are no large variances in the output and analytics found here.

\section{NOTES}

1. The Markowitz article, "Portfolio Selection," from The Journal of Finance (Volume 7, 1952), laying out his formulation of the Efficient Frontier, has been cited over 40,000 times in scholarly journals, indicating the extent of acceptance of "Portfolio Selection" as a bedrock of MPT.

2. The Dah, Hoque and Wang (2015) data includes price and value information on mutual funds from Kuwait, Malaysia, Saudi Arabia and the United States in every asset category, from sukuk to murabaha to equity funds (representing, respectively, 
their conventional equivalents in bonds, money market and equity investing). The practicality of investing simultaneously in these jurisdictions is questionable, since no one could easily cross these borders and make these investments. Further, it's not clear that the authors understand the difference between a money market fund and an equity fund, and whether money market and sukuk (bond equivalent) funds are properly inserted in analysis against equity market indexes. In other words, this is a keen example of scholars with little knowledge of real-world capital markets, putting into question the validity of their findings. Happily, the significant results of this work mostly relate to two very large U.S. Islamic equity funds and their relation to equivalent U.S. equity indexes, where the scholarship is legible and appears valid.

3. TheCityUK UK Fund Management tallies year-end conventional (pension, mutual funds and insurance), alternatives (hedge funds, private equity, ETFs and SWFs) and net private wealth (year-end 2016). See https://www.thecityuk.com/assets/ 2018/Reports-PDF/fe6b3af4b4/UK-fund-management.pdf. According to a different definition from Boston Consulting Group's Global Asset Management 2018 (summing AUM, based on fees paid), global AUM is $\$ 79$ trillion (year-end 2017). See http://image-src.bcg.com/Images/BCG-The-Digital-Metamorphosis-July -2018-R_tcm30-197509.pdf. The large disparity makes it difficult to ascertain the true volume of professionally managed AUM, but clearly it is in the tens of trillions of dollars, or more.

4. According to Credit Suisse Global Wealth Report 2018, see https://www.credit -suisse.com/corporate/en/articles/news-and-expertise/global-wealth-report-2018 -us-and-china-in-the-lead-201810.html.

5. International Monetary Fund, April 2015, see https://www.imf.org/external/pubs/ $\mathrm{ft} / \mathrm{gfsr} / 2015 / 01 / \mathrm{pdf} / \mathrm{c} 3 . \mathrm{pdf}$.

6. Investment Company Institute, Investment Company Fact Book 2018, p. 274, https://sfama-cms.cdn.prismic.io/sfama-cms\%2F37597afa-0cb7-4434-b04d -dabe83976e90_ici+investment+company+factbook+2018.pdf.

7. Almost $13 \%$ of the $\$ 18$ trillion mutual fund assets in the United States are owned by institutional investors. Ibid., p. 267.

8. This data is extracted from various easy-to-obtain Internet sources, either professional media or official government statistics. Source: Investment Company Institute, Investment Company Fact Book 2018, page 274.

9. See a lively recitation of the final recognition of Treynor's contribution to determinants of asset pricing in French (2003).

10. Although in Fabozzi et al. (2002) the authors took great pains to explain that MPT does not rely on an asset pricing model, and is perfectly valid without an asset pricing model.

11. Jorion (1992) also makes a thoughtful expression of the limitations inherent in mean-variance testing, the main one being time. As with so many applications in statistics, a meaningful dataset is often only obtained over long time periods. But even then there is a tradeoff between precision and validity, showing again how difficult it is to obtain correct weights of each asset category in a globally diversified portfolio.

12. Lummer and Reipe (1994) is arguably not academic nor scholarly. It is from a trade publication. But the piece neatly summarizes the professional practice of asset allocation at the time it was written, and the evolution to that date of mean-variance optimization. 
13. Only 52 citations noted in Google Scholar, but still a fascinating rebuttal to MPT critics.

14. This article is a layman's summary of Xiong et al. (2010).

15. PBUH.

16. Which is why CAPM is universally used by portfolio managers in Saudi Arabia, Indonesia and Nigeria, where portfolio managers use off-the-shelf optimization software that embeds the formulations of CAPM, such as the Bloomberg module PORT, or the optimization tools from Zephyr or AlternativeSoft, among many others.

17. Ibid., see in particular the discussions on the flexibility of sharia interpretations as they apply in finance.

18. "Sharia scholar's place on the board: Interview with top sharia scholars," Gulf News, 13 August 2010. https://gulfnews.com/business/a-sharia-scholars-place-on -the-board-1.625445.

19. See one of the foundation texts on Islamic finance, An Introduction to Islamic Finance (Usmani, 2002). For reference, Sheikh Usmani was later Secretary General of the Accounting and Audit Organization of Islamic Financial Institutions (AAOIFI), a quasi-regulator of Islamic finance, when he repeated the above in his famous fatwa on sukuk in November 2007 (in Arabic) and February 2008 (in English), a seminal date in Islamic finance as it changed the permissible structure of sukuk forever.

20. On various online forums related to Islamic finance, some Muslims make the argument that the introduction of a risk-free rate implies interest (riba) is embedded in MPT. However, one can argue that the social cost of capital is an equivalent to, or at least a proximate substitute for, the risk-free rate, thereby satisfying the avoidance of riba in theory. Another argument may be that governments who borrow using asset-backed sukuk - which are widely approved by prominent sharia scholars and now includes Luxembourg, Hong Kong, South Africa and the United Kingdom - themselves create a risk-free rate.

21. The general concept and indeed specific ideas of this table were taken from Maginn et al. (2007). However, these concepts are generic in nature and widely used in asset management.

22. Hereinafter simply Reuters.

23. "Global spend on market data, news tops $\$ 28 \mathrm{~B}$," from https://www.marketsmedia .com/global-spend-on-market-data-news-tops-28b/ and "Demand for financial market data and news up $4.07 \%$ in 2014, highest since 2011," from http://www .prnewswire.com/news-releases/demand-for-financial-market-data--news-up-407 -in-2014-highest-since-2011----burton-taylor-report-300054093.html. 